\title{
Inverter Power Stage Connected with PV-Grid
}

\author{
K. Kirubasankar1, Dr. A. Senthil Kumar² \\ ${ }^{1}$ Chennai Institute of Technology, Chennai, India \\ ${ }^{2}$ Velammal Engineering College, Chennai, India \\ Email:kirubasnkr@yahoo.co.in,vastham@gmail.com
}

How to cite this paper: Kirubasankar, K. and Kumar, Dr.A.S. (2016) Inverter Power Stage Connected with PV-Grid. Circuits and Systems, 7, 4113-4123. http://dx.doi.org/10.4236/cs.2016.713339

Received: May 6, 2016

Accepted: May 21, 2016

Published: November 16, 2016

Copyright $\odot 2016$ by authors and Scientific Research Publishing Inc. This work is licensed under the Creative Commons Attribution International License (CC BY 4.0).

http://creativecommons.org/licenses/by/4.0/

\begin{abstract}
This paper focuses on the design of the inverter power stage connected with PV-grid which supports the contrived PV system. The increased number of grid connected photovoltaic (PV) inverters gave rise to problems concerning the stability and safety of the utility grid, as well as power quality issues. The proposed systems can overcome these issues and improve standard regulation methods for gird connected PV inverter. The maximum available voltage in the PV string is tracked by the power stage which has been planned and designed in such a way. The tracked voltage is boosted then. The important components to voltage source inverter (VSI) are boost inductor and input capacitor which are calculated. To get a clear sinusoidal output phase voltage of $230 \mathrm{~V}$ from a DC capacitance bus projected to deal with $400 \mathrm{~V}$, the important inverter stage parameters have been planned and modeled in Mat lab. Each block stage of the converter is easily understandable by the Simlink of the dual stage DC-AC converter explanation. The control schemes which have been proposed would compromise with the inverter power stage which forms the neat grid system. The existing renewable energy sources in the laboratory are integrated by the proposed control.
\end{abstract}

\section{Keywords}

PV-Grid, Maximum Power Point Tracking, Inverter Power Stage, Converter

\section{Introduction}

According to temperature and irradiance, the characteristics of solar affect the open circuit voltage. The PV-grid connected systems' standards to model and install are discussed which helps to contrive the PV system. Proposed a grid connected photovoltaic fly back inverter operation in DCM, with combinations of fractional short circuit current and hill climbing [1], issues in PV system like over voltage, reverse power flow problem, are solved and implemented coordinated power point tracking (CPPT), opti- 
mization problem formulated to overcome reverse power flow [2]. An interleaved fly back converter is proposed, and a forward compensation circuit is implemented to eliminate the distortion at primary side with an output filter design [3]. A digital implementation of control loops of typical 2 stage PV interface using a low power renewable energy developing kits in steady state and transient conditions analysis are made [4]. Power system stability and energy conversion efficiency that is proposed with distributed maximum power point tracking techniques are proposed [5]. A conventional maximum power point tracking is proposed with algorithm on particle swarm optimization that is capable of tracking global MPP under partial shaded conditions [6]. A novel solar power plant is modeled with perturbs and observes algorithm that is used for MPP tracker implementation. The performances analyses are carried out [7]. A new topology proposed is capable of energy diversification among different energy sources using bidirectional devices [8]. Hierarchical control for DC and AC microgrids proposed [9]. A reconfiguration strategy proposed for PV systems to achieve maximum power generation from non-uniformly aged PV module [10]. Grid with PV inverters, owing to the growth of world's power demand, the necessity of using grid connecter photovoltaic power supply has become transparent. To arrange PV system into the grid, the capable technology is solid-state inverters. Producing power supply by integrating PV power generation is eco-friendly. PV panel and a DC/AC converter are components of the PV system which has been connected to the grid. This system helps to generate power to the places and sites. If the PV system produces excess AC power more than the need, it can be sent to other user by the inverter. According to the requirements and application, PV system can be set as a standalone or hybrid system. The various methods of power utilization will be met out by the concept of power grid. Higher efficient smart grids are being scheduled worldwide. The traditional power grid has been replaced by the smart grid by new technologies and services. There are so many MPPT methods named perturb, incremental, observe, neural network and fuzzy logic control. Each method has its own pros and cons. According to the fluctuations of weather conditions, these methods are used effectively in both standalone and gridconnected PV solar energy systems. The maximum power point tracker (MPPT) is essential for utilizing the maximum power produced by the PV modules. It is a device that tracks the maximum power utilized location at all. DC-DC converter is designed with the MPPT and it is included in the DC-AC inverter control when there is no DC-DC converter. Maximum voltage, VMP and maximum current, Imp of the modules is attained and produces maximum power, PMP point which has been operated by the PV modules with the help of MPPT. Grid connected PV systems are dealt by various technologies and topologies. The number of power stages categorizes the systems. Figure 1 shows the PV grid connected system configuration with different types of inverters. There are numerous technological concepts applied in the PV plants applications to connect PV array with utility grid. Each \& every technology has its own pros and cons when it is compared to other technology sticking to the terns of efficiency and maximum power point tracking. 


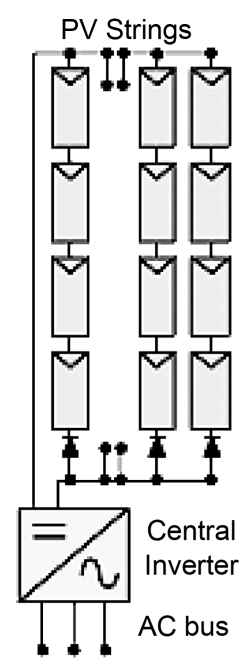

(a)

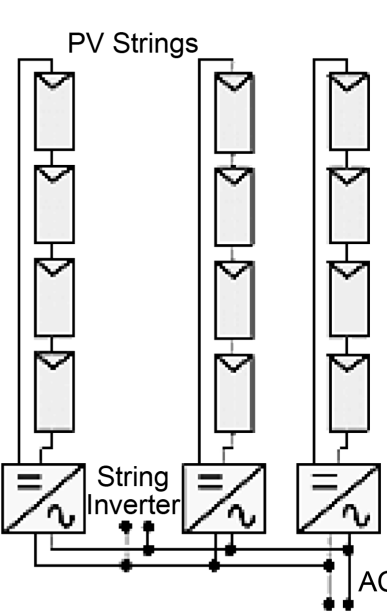

(b)

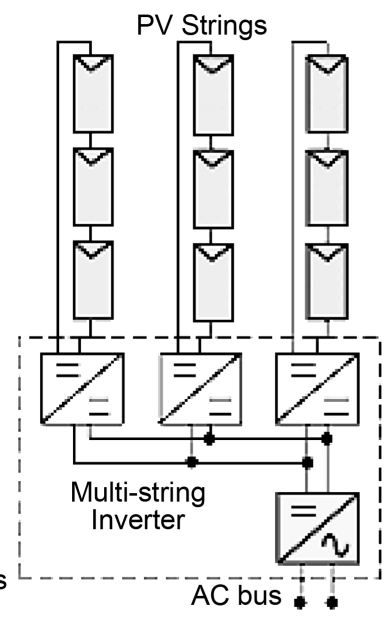

(c)

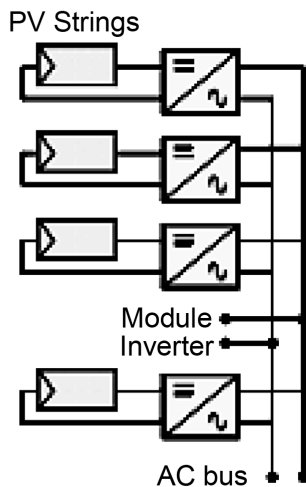

(d)

Figure 1. PV grid connected systems configurations. (a) Central inverters. (b) String inverters. (c) Multistring inverters. (d) Module inverters.

\section{Methodology}

\subsection{Inverter Power Stage Topologies}

\section{DC-DC converter topologies}

In day to day usage, the role of DC-DC converters is ceaselessly increasing. DC power supply is one of the paramount uses of converters. It is enumerated that there are three basic types of DC/DC converters and the product of these converters are Cuk converters and Full bridge converters. Probably the inverters comprise of the boost converter, buck converter respectively as a step-up converter and step down converter in order to have higher output and lower output and a buck-boost converter is either to reduce or to increase the voltage ratio with a unit gain for a duty ratio of $50 \%$. The grid connected PV inverter's power stage uses full bridge switch mode DC-DC converter. Half-Bridge Converter is another configuration for providing high voltages. Provided with higher efficiency it has only two switches wit simpler structure but it produces half output voltage of the Push-Pull Converter. The sensitivity to the load variations is another main drawback of this design. In order to put up the rapid change of the voltage ratio a more complex control circuit is needed. Attaining regulated output within desired constraints is very difficult and losing switches with current changes are other main problems on this topology. Circuit symmetric results in a more complex control circuit design moreover it is difficult to achieve.

\subsection{DC-DC Converter}

Discussing different converter topologies in detail, DC-DC converter is felt feasible. Unstable and low voltage from the PV array through the input capacitor PV C to a constant $400 \mathrm{~V}$ DC voltage at the capacitor link, DC C is converted by the DC-DC converter in the DC-DC input stage. Figure 2 shows the full bridge DC-DC converter topology. There are numerous advantages in the topology, primarily its power handling 
capabilities, stability, and symmetry are very useful on having a Full-Bridge DC/DC converter in the DC to DC stage.

\subsection{DC-AC Inverter}

Full bridge inverter is used in this proposed circuit; DC power is converted into AC power in this DC-AC stage at preferred output voltage and frequency. The $400 \mathrm{~V} \mathrm{DC}$ output voltage of the full bridge converter is converted to the grid voltage of $230 \mathrm{~V} \mathrm{AC}-$ $240 \mathrm{~V} \mathrm{AC}$ at $50 \mathrm{~Hz} / 60 \mathrm{~Hz}$ frequency by the designed power stage. Accessing same input voltage, the full-bridge inverter produces an output power twice that of the half-bridge inverter. Four switching devices are shown in Figure 3, the single phase full bridge topology, two of which are on each leg. When transformation between DC and AC voltage is needed single-phase converters are used; exclusively when the converters transfer power back and forth between DC and AC. While switching the full-bridge in an appropriate sequence it creates an unfiltered output voltage. Sticking to the fact how the switches are controlled, the output voltage of the bridge, $a b V$ can be either be $+V d, d-V$ or 0 voltage is produced. The input voltage $d V$ at the DC link or bus link capacitor $C$ is a fixed-magnitude voltage and the output voltage is $a b V$ it is controlled in both polarity and magnitude.

\subsection{Grid Connected PV Inverter}

\section{Input and DC-link capacitors}

The means of electrolytic capacitor enables DC link capacitor to decouple power. After

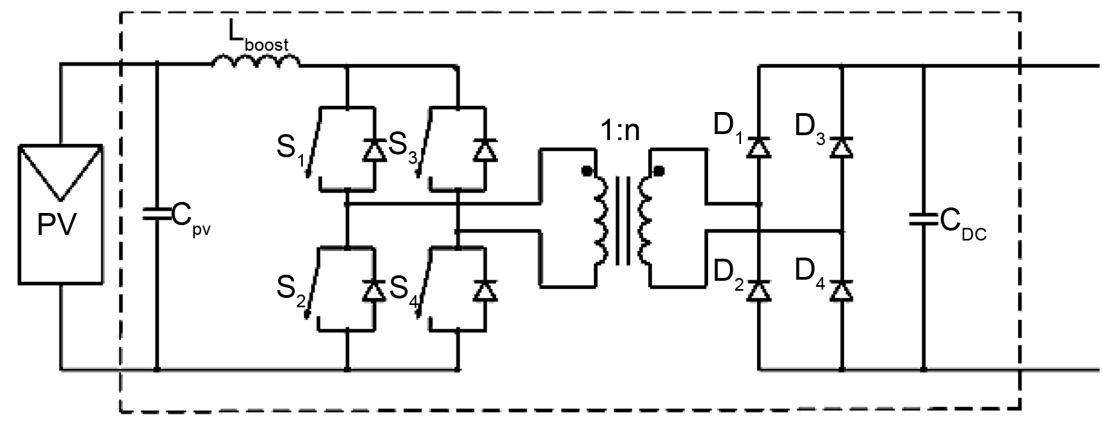

Figure 2. Full bridge DC-DC converter topology.

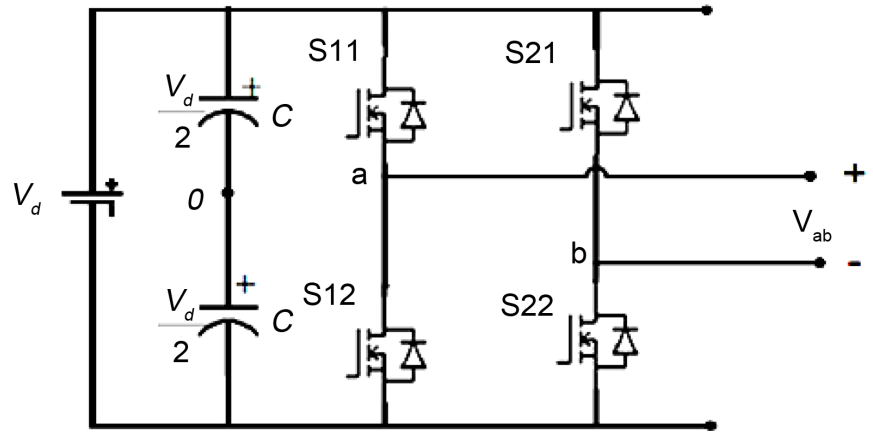

Figure 3. Single phase full bridge inverter. 
several years, electrolytic capacitor technology has been chosen by design engineers to use it as a bus link capacitor in inverter designs.

Electrolytic capacitors are the eminent technology for hard switched inverter bus link capacitors. The technology of electrolytic capacitor remains same for several years. The electrolytic capacitors costs low that the technology gets the center of attraction for choosing it. The DC link capacitor plays a vital role in the long life of the converter and it is substituted with film capacitor and kept as possibly small. Intended to reduce DC-link capacitance of inverters, many toils have been taken that film capacitors have been proposed to replace electrolytic capacitors. Were compared and explained.

\subsection{Input Inductance and Capacitance}

Earlier sections explained the significance and inevitability of the input parameters which parameters are boost inductor or DC inductor PV L and input capacitor PV C. On estimating these parameters direct formulae have been used. There are two strings in the system which has been set in a series for having voltage of $40 \mathrm{~V}$ and it is connected in parallel for attaining 10 a current. V-I characteristics of the NTNU PV array is affected by irradiance and temperature. MPPT performance is affected by these changes so it has to be minded in the design. $15 \%$ of the solar radiation is converted into electricity by PV cells and it is hard to attain the preferred $420 \mathrm{~V}$ from the PV array. Considering the reasons, $100 \mathrm{~V}$ is taken as minimum available voltage at any time. Duty ratio is calculated with the usage of minimum voltage because it renders maximum switching current. This duty ratio $\mathrm{D}=0.68$ is noteworthy to the full bridge converter. $85 \%$ is assumed as the efficiency of the converter at any worst case.

\subsection{Input Inductance, $L_{P V}$}

Many designs show the inductor in a certain range provided. Calculating the boost inductor directly is advised when data sheet is not available. $20 \%$ to $40 \%$ of the output current is calculated as the inductor ripple current. In this assumed design input voltage is estimated to be $V_{P V}=100 \mathrm{~V}$ and the estimated switching frequency is $f=10 \mathrm{kHz}$. The value of projected inductor ripple current can be found by using equation. On assuming the continuous conduction mode, (CCM) of the boost converter stage, the boost inductor is estimated using equation. by assuming the cause of $20 \%$ approximation and is established to be, $L_{P V}=0.2 \mathrm{mH}$.

$$
L_{p v}=\frac{V_{\text {in }} *\left(V_{\text {out }}-V_{\text {in }}\right)}{\Delta L_{v} * V_{\text {out }} * f_{s}}
$$

\subsection{Input Capacitance, $C_{P V}$}

On obtaining the boost inductor, the input capacitance also can easily be obtained. The continuous conduction mode (CCM) of the boost converter is assumed by the analysis. The capacitance see the voltage ripple from the PV array MPP as $\Delta V_{p v}$ according to the variation of temperature and irradiance. Since temperature changes from $-20^{\circ} \mathrm{C}$ to $40^{\circ} \mathrm{C}$, the open circuit voltages changes. Consequently the open circuit of the PV string 
voltage change is by, $\Delta V_{p v}=5 \mathrm{~V}$. Thus, $\mathrm{PV}$ input capacitance is significant to voltage source inverters (VSI). The model of the PV modules is converted and it becomes voltage source to the inverter. It maintains the voltage stable and decreases power fluctuation at the input.

$$
\Delta p_{p v}=\frac{D * V_{P V}}{4 * f_{s}^{2} * L_{p v} * C_{p v}}
$$

\subsection{DC-Link Design}

$230 \mathrm{~V}$ is the mentioned output AC voltage of the inverter as VSI single phase. According to this value, the estimated voltage value of $400 \mathrm{~V}$ at the DC bus is attained. At the DC link capacitance this voltage is viewed and it is called as power coupling capacitor. Using Equation (2), the DC link voltage is assumed as the bus voltage, bus V. 10\% from the bus voltage or link voltage is the ripple voltage in this design. Sticking to the reason, $10 \%$ is given and the approximated DC bus voltage of $400 \mathrm{~V}$ is attained. Besides the benefits discussed already, the paramount function of the. The net nominal power from the strings is assumed as $P_{P V}=1 \mathrm{~kW}$ at the input voltage $V_{P V}=220 \mathrm{~V}$ is to be the output and it is to be delivered to the DC bus. On account of substituting the grid frequency of $50 \mathrm{~Hz}$ the value of DC link capacitor $C_{D C}=100 \mu \mathrm{F}$ is contrived. The summary of the calculated values are given in Table 1. At convinced rated voltages Standard values for these parameters are chosen in the design methodologies. The parameters standardization is not considered. The design uses original calculated values.

$$
V_{\text {bus }}=\sqrt{2} * 230+10 \% 230=358 \rightarrow 400 V
$$

\subsection{Parameter Value}

\section{Control strategies of the inverter power stage}

In order to control voltage source, VSI power stage, various techniques are mentioned. Including hysteresis band, predictive, and sinusoidal pulse width modulation (SPWM) control, it is three important output current control techniques for the single phase VSI. Various techniques of PWM are explored in which one is concentrated and it will be considered the very apt one to control the inverter power stage. On the technique Pulse Width Modulation (PWM), The DC-AC inverters are usually operated.

Table. 1. Parameters of SPWM.

\begin{tabular}{cc}
\hline Parameter & Value \\
\hline Duty ratio & 0.68 \\
Switching frequency & $10 \mathrm{kHz}$ \\
Input inductance, $L_{p V}$ & $0.2 \mathrm{mH}$ \\
Input capacitance, $C_{p V}$ & $170 \mu \mathrm{F}$ \\
DC-Link capacitance, $C_{D C}$ & $100 \mu \mathrm{F}$ \\
Ripple voltage, $\Delta V$ & $40 \mathrm{~V}$
\end{tabular}




\subsection{Sinusoidal Pulse Width Modulation (SPWM)}

This modulation technique has multiple numbers of output pulses per half cycle and the pulses have different width. According to the amplitude of a sine wave calculated at the centre of the same pulse, the width of each pulse is varying in proportionately. Having compared a sinusoidal reference signal with a high frequency triangular signal, the gating signals are generated. The inverter output voltage is determined by the reference signal frequency. According to the SPWM generating techniques, the triangle waveform tri $V$ is at switching frequency $s \oint$, this frequency restricts the speed at which the inverter switches are turned on and off. The control signal control $V$ is applied to modulate the switch duty ratio and has a frequency $1 f$. This is the basic frequency of the inverter output voltage. Switching frequency affects the output of the inverter that results in harmonics at the switching frequency.

\subsection{Switching of the Inverter Power Stage}

The power stage inverter is controlled and switched by IP cores. Generating $10 \mathrm{kHz}$ switching frequency FPGA DDS Triangle Gen IP.vi is used. On comparing the phase sine wave signal from the grid, the pulses are obtained. This comparison output is fed into the inverter power stage for scheming opening and closure of the switches. The signals of the switches SW 1 to SW 4 of the DC to DC stage open/close switches TSW 1 to TSW 4 and signals of the switches $\mathrm{s} 1$ to $\mathrm{s} 4$ of the DC to AC stage open/close switches TS 1 to TS 4 are restricted by SPWM with the help of voltage switching. Each leg is controlled autonomously of the other. 0.68 is the set duty ratio to maintain the ratios of the pulses to the switches. The switches SW 3 and SW 4 are closed and opened by the pulses. PWM switching pulses as simulated in mat lab.

\section{Simulation and Experimental Results}

\subsection{System Description}

The designed dual power stage is shown in Figure 4 and in Figure 5 inverter power stage with PI controller which has the described ratings. Based on the discussion mentioned above, the inverter is designed. The assumed fixed voltage from the PV array is calculated as $100 \mathrm{~V}$, this is considered as the only voltage available all the time at the PV arrays. Using the full bridge single phase inverter, the voltage is amplified and the inverter provides galvanic isolation between the PV array and the grid. Accessing the preferred output AC voltage of $230 \mathrm{~V}, 400 \mathrm{~V}$ DC-Link voltage is estimated. The maintained DC-bus voltage is the secondary of the transformer with turn ratio of 1:1.3 and MPPT controller controls it. The harmonics are minimized by the designed filter which has been located in the inverter output.

\subsection{System Control}

The implemented inverter power stage its circuitry design is designed by Matlab. The circuits are controlled by MATLAB and it is made as a suitable user interface. The generated IPWM from the IP cores controls output voltage of the inverter. The different 


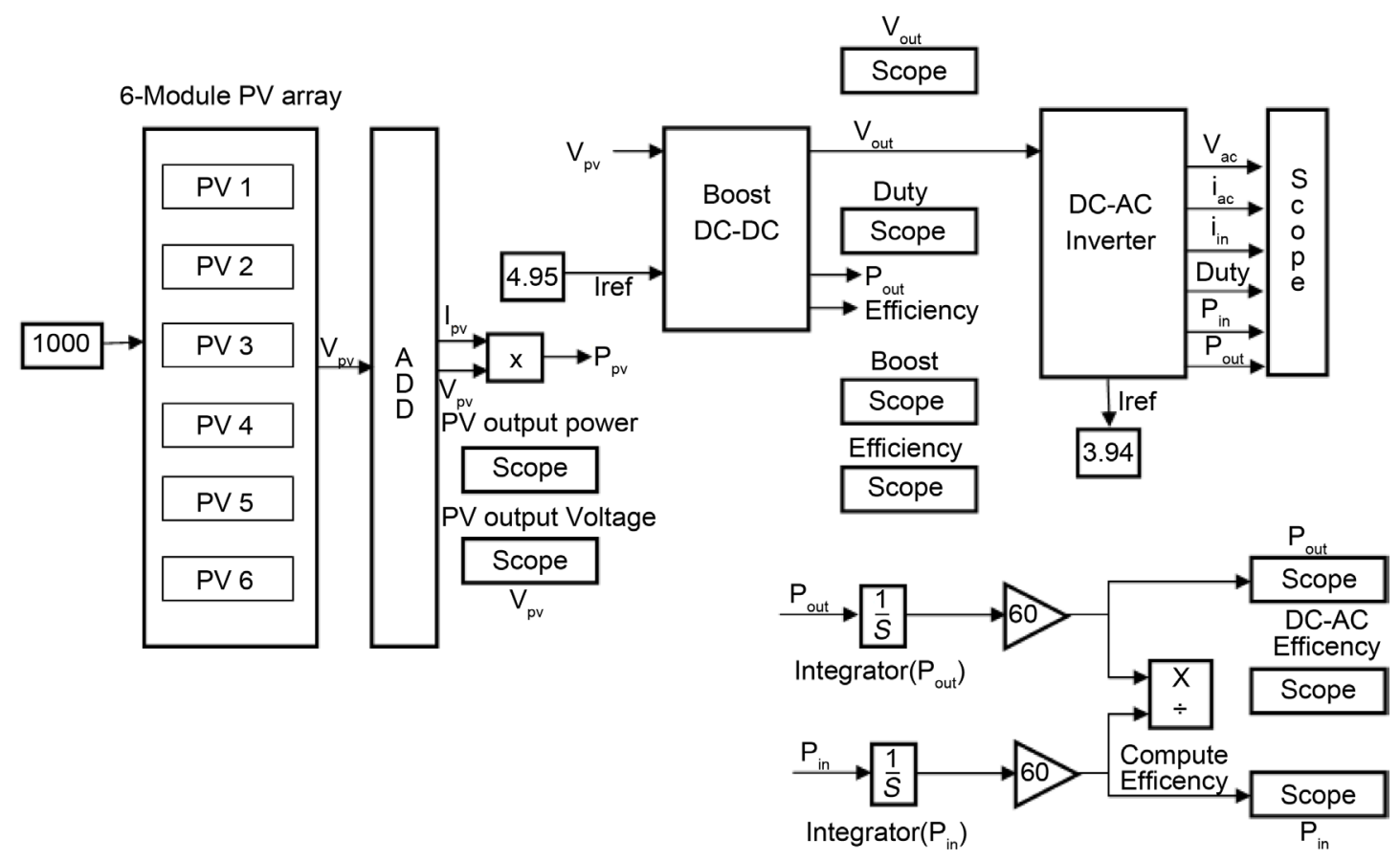

Figure 4. Proposed inverter power stage.

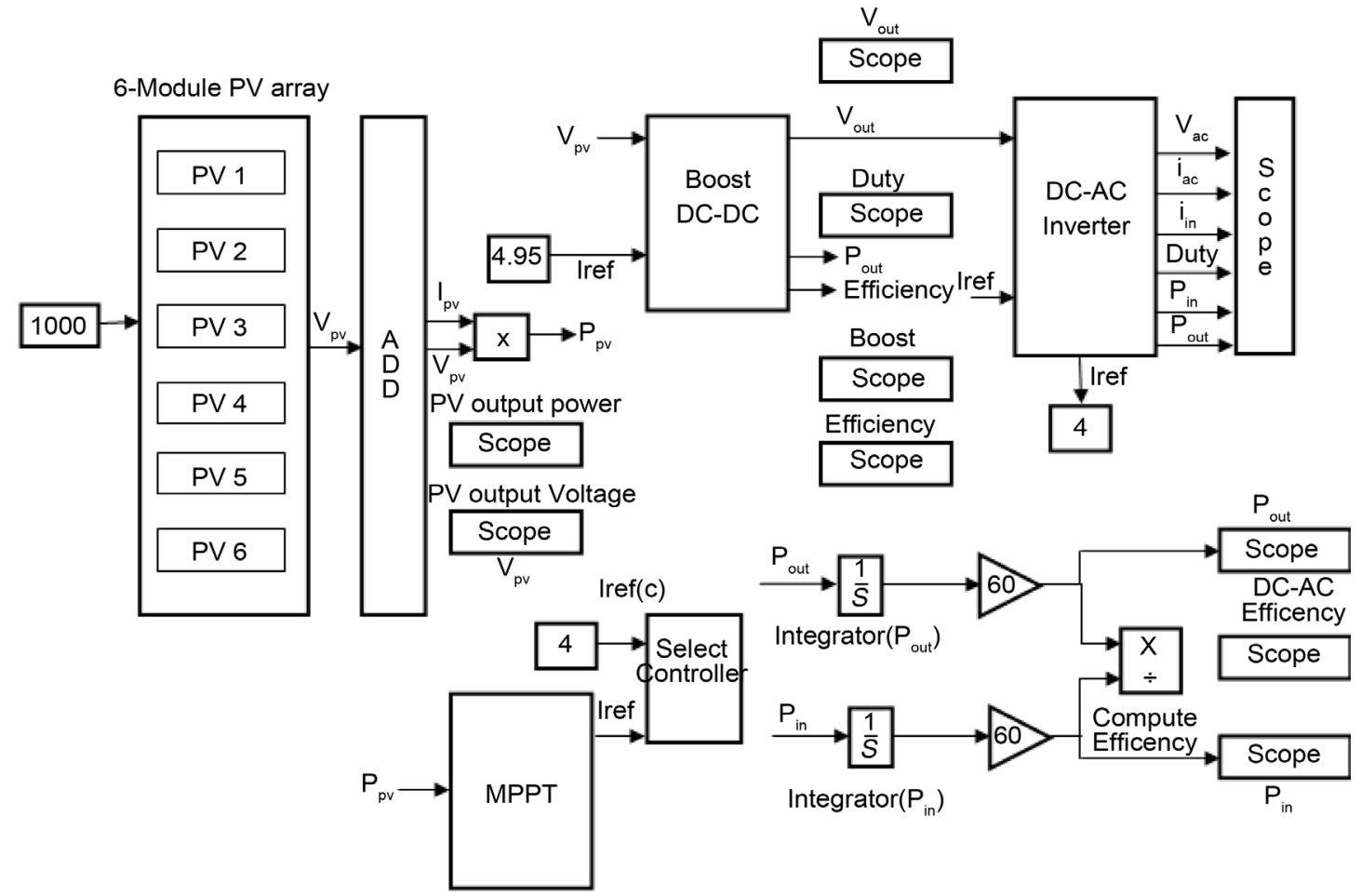

Figure 5. Proposed inverter power stage with PI controller.

control function blocks are illustrated clearly in Figure 4. The inverter output is converted into RMS value with help of function blocks in the control system. When simulation promotes grid frequency $50 \mathrm{~Hz}$, it gives frequency every time. One phase 
of the three phase grid is taken for comparing with the inverter outputs and switching signal generation, which is output voltage of the power stage inverter. Max out voltage of amplitude switched to more or less between 0 and $500 \mathrm{~V}$. Between positive and negative peak of the DC-link voltage the output of the inverter is switched, when the parameters of the inverter attains stable state. To minimize the distortions, the voltage is filtered.

\subsection{Inverter Output and Grid Voltage}

The output waveform of the inverter with power stage is shown in Figures 6-8. It can be seen that the phase output voltage with pure sinusoidal waveform.

\section{Conclusion}

This paper is focused on modeling and MPPT technology device grid connected Photovoltatic system. A causal information method and its proprieties are permitted to determine all elementary models and to calculate the PV-side and grid-side controllers. In this way, an MPPT controller is used to take out the most favorable photovoltaic power. A current and a dc link voltage regulator are used to transfer the photovoltatic power and to synchronize the output voltage with the grid system. The simulated model and

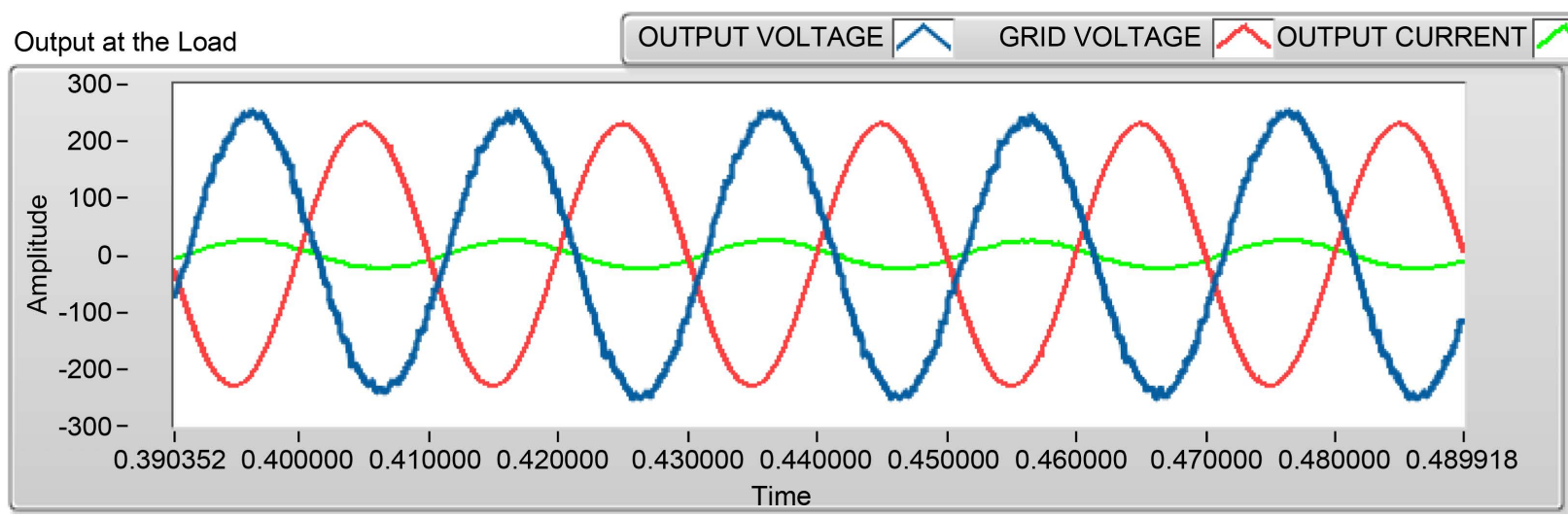

Figure 6. Inverter output voltage and current with gird voltage.

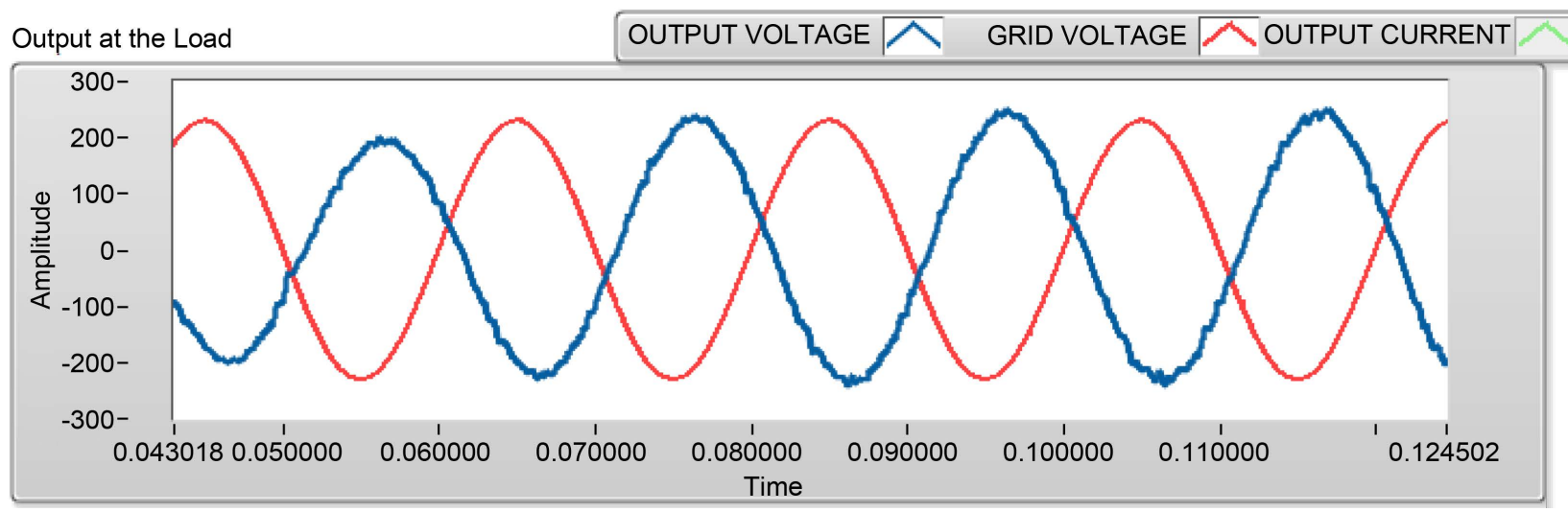

Figure 7. Grid voltage and inverter output voltage. 


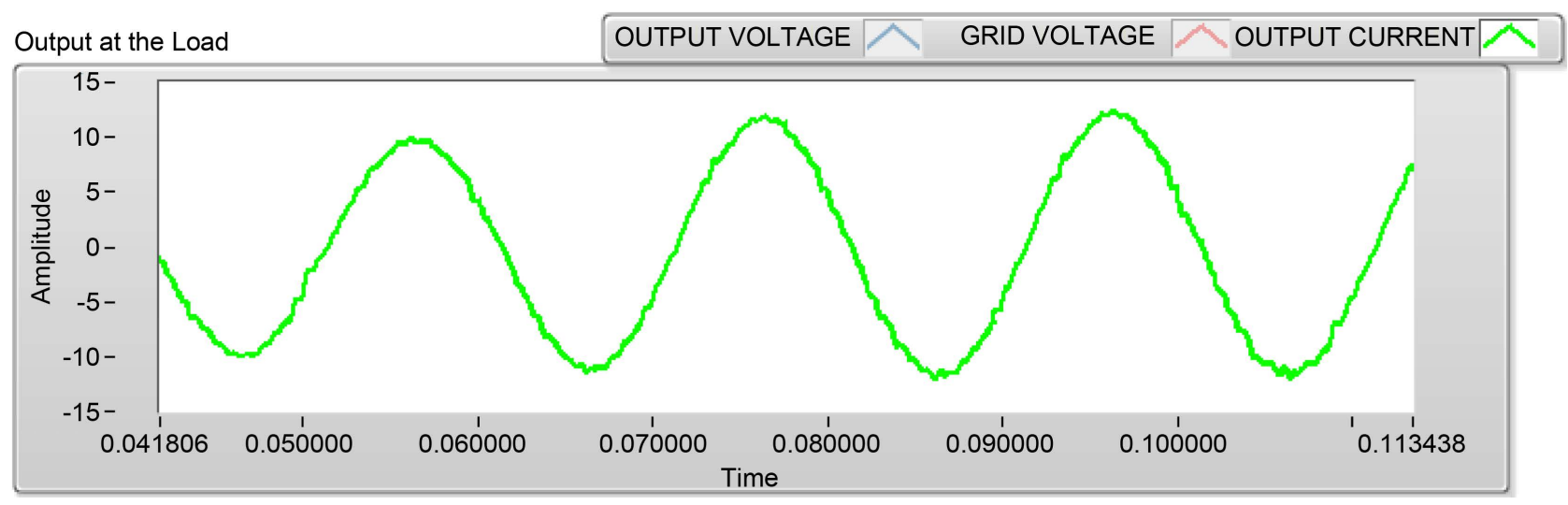

Figure 8. Inverter output voltage and current with grid voltage.

the results obtained for standard operating conditions are shown the performances of the grid connected photovoltaic.

\section{References}

[1] Sher, H.A., Addoweesh, K.E. and Al-Haddad, K. (2015) Performance Enhancement of a Flyback Photovoltaic Inverter Using Hybrid Maximum Power Point Tracking. IEEE Industrial Electronics Society, Yokohama, 9 November 2015, 005369-005373.

[2] Wang, X.D., Pi, Y.B., Mao, W.G. and Huang, H. (2014) Network Coordinated Power Point Tracking for Grid-Connected Photovoltaic Systems. IEEE Journal on Selected Areas in Communications, 32, 1425-1440. http://dx.doi.org/10.1109/JSAC.2014.2332120

[3] Hsieh, H.-I., Hsieh, G.-C. and Hou, J.X. (2014) Realization Study of Interleaved PV Microinverter by Quadrature-Phase-Shift SPWM Control. IEEE International Power Electronics Conference, Hiroshima, 526-531.

[4] Chaves, H., Grigulo, J., Bertagnolli, L. and Lopes, L.A.C. (2014) 2-Stage Grid-Connected and Stand-Alone PV Inverter Implemented with a Renewable Energy Developer's KIT. Proceedings of IEEE International Instrumentation and Measurement Technology Conference (I2MTC), Montevideo, 631-636.

[5] Jiang, Y.C., Qahouq, J.A.A. and Orabi, M. (2012) AC PV Solar System Distributed Architecture with Maximum Power Point Tracking. IEEE Intelec 2012, Scottsdale, 1-5.

[6] Ishaque, K., Salam, Z., Taheri, H. and Shamsudin, A. (2011) Maximum Power Point Tracking for PV System under Partial Shading Condition via Particle Swarm Optimization. IEEE Applied Power Electronics Colloquium, Malaysia, 19 April 2011, 5-9.

[7] Natsheh, E.M. and Albarbar, A. (2011) Photovoltaic Model with MPP Tracker for Standalone/Grid Connected Applications. IEEE Renewable Power Generation, Edinburgh, 6-8 September 2011, 1-6.

[8] Khaligh, A., Cao, J. and Lee, Y.J. (2009) A Multi-Input DC-DC Converter Topology. IEEE Transactions on Power Electronics, 24, 862-868. http://dx.doi.org/10.1109/TPEL.2008.2009308

[9] Guerrero, J.M., Vasquez, J.C., Matas, J., de Vicuna, L.G. and Castilla, M. (2011) Hierarchical Control of Droop-Controlled AC and DC Microgrids: A General Approach toward Standardization. IEEE Transaction on Industrial Electronics, 58, 158-172. http://dx.doi.org/10.1109/TIE.2010.2066534

[10] Houssamo, I., Locment, F. and Sechilariu, M. (2013) Experimental Analysis of Impact of 
MPPT Methods on Energy Efficiency for Photovoltaic Power Systems. International Journal of Electrical Power \& Energy Systems, 46, 98-107.

http://dx.doi.org/10.1016/j.ijepes.2012.10.048

Submit or recommend next manuscript to SCIRP and we will provide best service for you:

Accepting pre-submission inquiries through Email, Facebook, LinkedIn, Twitter, etc.

A wide selection of journals (inclusive of 9 subjects, more than 200 journals)

Providing 24-hour high-quality service

User-friendly online submission system

Fair and swift peer-review system

Efficient typesetting and proofreading procedure

Display of the result of downloads and visits, as well as the number of cited articles

Maximum dissemination of your research work

Submit your manuscript at: http://papersubmission.scirp.org/

Or contact cs@scirp.org 